\title{
Comparison of Endothelium-Dependent Responses of Canine Internal Thoracic and Coronary Arteries
}

\author{
Shoichiro Shiraishi ${ }^{1}$, Atsumi Mori ${ }^{2}$ and Noboru Toda ${ }^{1, *}$ \\ 'Department of Pharmacology and 'Second Department of Surgery, Shiga University of Medical Science, Seta, Ohtsu 520-21, Japan \\ Received November 17, 1992 Accepted December 11, 1992
}

\begin{abstract}
The endothelium-dependency of vasodilator responses was compared in helical strips of canine internal thoracic (ITA) and coronary arteries partially contracted with serotonin. The addition of acetylcholine produced a concentration-related relaxation in ITA and coronary arterial strips with an intact endothelium. The relaxations were not influenced by indomethacin, but were markedly inhibited or abolished by methylene blue, $N^{G}$-nitro-L-arginine (L-NA), a nitric oxide (NO) synthase inhibitor, and endothelial denudation. The responses to low concentrations of acetylcholine were significantly greater in ITA than in coronary arteries, whereas relaxations induced by substance $\mathrm{P}, \mathrm{Ca}^{2+}$ ionophore (A23187) or NO in ITA were significantly less. The substance P-induced relaxation in ITA and coronary arteries was endotheliumdependent, and it was almost abolished by L-NA. Relaxations induced by ATP in ITA were abolished by endothelium denudation and treatment with L-NA. In the coronary arteries, relaxing responses were inhibited only partially by removal of endothelium and L-NA. Acetylcholine, ATP and substance P relax canine ITA possibly by a mediation of endothelium-derived NO, but not prostaglandin $\mathrm{I}_{2}$. Coronary arterial relaxations induced by ATP appear to be mediated by an indirect action via NO released from the endothelium, in addition to a direct action on the smooth muscle.
\end{abstract}

Keywords: Endothelium-derived relaxing factor (EDRF), Nitric oxide (NO), Internal thoracic artery (ITA), Coronary artery

The internal thoracic artery (ITA) is becoming the conduit of choice for coronary artery bypass grafting (CABG). The ITA graft has demonstrated superior patency over the saphenous vein graft $(1,2)$. Numerous references have suggested that survival is superior when the ITA rather than a saphenous vein is used $(3,4)$. The ITA is a 'living' conduit with the intact endothelium and appears to develop atherosclerosis later than do native coronary arteries (5). These characteristics may contribute to the ITA's high, long-term patency rate.

Since the discovery by Furchgott and Zawadzki (6), the functional importance of endothelium-derived relaxing factor (EDRF) as a powerful, physiological vasodilator has been widely accepted. Thus, EDRF, together with the other endogenous vasodilators, may participate in the protection from occlusion of the grafts and vasospasm of coronary arteries.

Chemical and physical stimulation of the endothelium

\footnotetext{
*To whom correspondence should be addressed.
}

liberates EDRF in many vasculatures from experimental animals. However, little information is available concerning the EDRF-releasing action of endogenous substances in ITA, as compared to that in coronary arteries. Therefore, the present study was undertaken to compare the responses of ITA and coronary arteries obtained from dogs to acetylcholine, ATP, substance $P$ and the $\mathrm{Ca}^{2+}$ ionophore A23187 and to determine their endotheliumdependency.

\section{MATERIALS AND METHODS}

\section{Preparation}

Mongrel dogs of either sex weighing 6 to $15 \mathrm{~kg}$ were anesthetized with intravenous injections of sodium pentobarbital $(30 \mathrm{mg} / \mathrm{kg}$ ) and sacrificed by bleeding from the common carotid arteries. The sternum and heart were rapidly removed, and ITA and coronary arteries (1.0-2.0 mm outside diameter) were carefully isolated within $30 \mathrm{~min}$ after death. The arteries were cut helically 
into strips approximately $20 \mathrm{~mm}$ long, with special care to preserve the endothelium. In some experiments, the endothelium was removed by gently rubbing the intimal surface with a cotton pellet; unrubbed strips from the same dogs were used for comparison. Removal of the endothelium was verified by abolishment of the relaxation caused by $10^{-6} \mathrm{M}$ acetylcholine and by $\mathrm{AgNO}_{3}$ staining. The specimens were fixed vertically between hooks in a muscle bath containing a modified Ringer-Locke solution kept at $37 \pm 0.3{ }^{\circ} \mathrm{C}$ and aerated with a mixture of $95 \% \mathrm{O}_{2}$ and $5 \%$ $\mathrm{CO}_{2}$. The hook anchoring the upper end of the strips was connected to the lever of a force-displacement transducer (Nihon Kohden Kogyo Co., Tokyo). The resting tension was adjusted to $1.5 \mathrm{~g}$, which is optimal for inducing the maximal contraction. Constituents of the solution were as follows: $120 \mathrm{mM} \mathrm{NaCl}, 5.4 \mathrm{mM} \mathrm{KCl}, 2.2 \mathrm{mM} \mathrm{CaCl}, 1.0$ $\mathrm{mM} \mathrm{MgCl}_{2}, 25.0 \mathrm{mM} \mathrm{NaHCO}$ and $5.6 \mathrm{mM}$ dextrose. The $\mathrm{pH}$ of the solution was 7.35 to 7.42 . Before the start of the experiments, all the preparations were allowed to equilibrate for 60 to $90 \mathrm{~min}$ in the bathing media, during which time the solutions were replaced every 10 to $15 \mathrm{~min}$.

\section{Recording}

Isometric contractions and relaxations were displayed on an ink-writing oscillograph (Nihon Kohden Kogyo
Co.). The contractile response to $30 \mathrm{mM} \mathrm{K}^{+}$was first obtained, and the preparations were washed 3 times with control media and equilibrated for $40-50 \mathrm{~min}$. The strips were partially contracted with serotonin (5-hydroxytryptamine: $5 \mathrm{HT}$ ), the contraction ranging between 20 to $30 \%$ of the contraction induced by $30 \mathrm{mM} \mathrm{K}^{+}$. Concentrationresponse curves for acetylcholine, nitric oxide (NO), ATP and $\mathrm{A} 23187$ were obtained by adding the drugs directly to the bathing media in cumulative concentrations. The response to substance $P$ was obtained by adding a single concentration $\left(10^{-7} \mathrm{M}\right)$ because of the development of tachyphylaxis. At the end of each series of experiments, papaverine $\left(10^{-4} \mathrm{M}\right)$ was applied to attain the maximal relaxation, which was taken as a standard for relaxation $(100 \%)$. In assessing the effects of blocking agents, the agonists were repeatedly applied, until the responses were stabilized. Then, the artery strips were treated for approximately $30 \mathrm{~min}$ with blocking agents.

\section{Statistics and drugs used}

The results shown in the text and figures are expressed as the mean value \pm S.E.M. Statistical analyses were performed by Student's $t$-test and Tukey's method after oneway analysis of variance. The response to NO was obtained by adding $\mathrm{NaNO}_{2}$ solution adjusted at $\mathrm{pH} 2(7)$.
INTERNAL THORACIC ARTERY

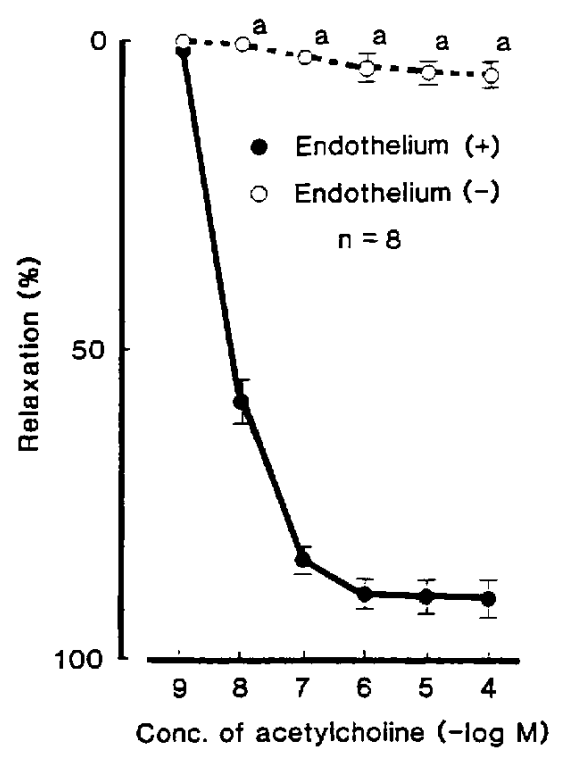

Endothelium ( + )

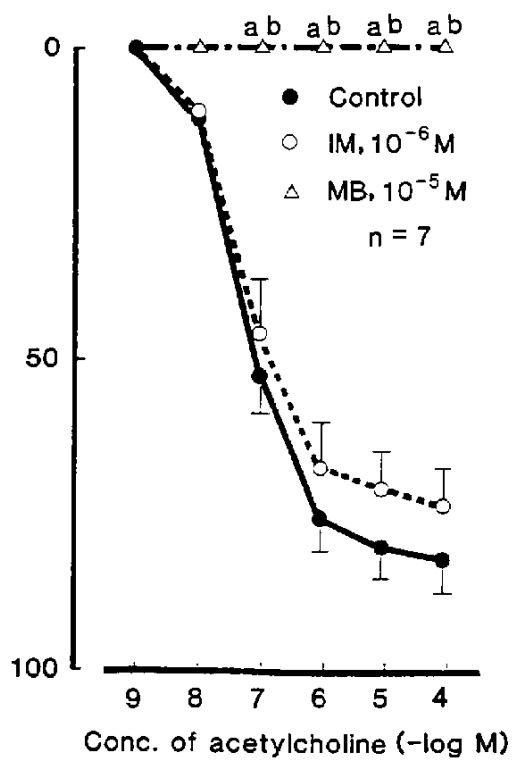

Endothelium (+)

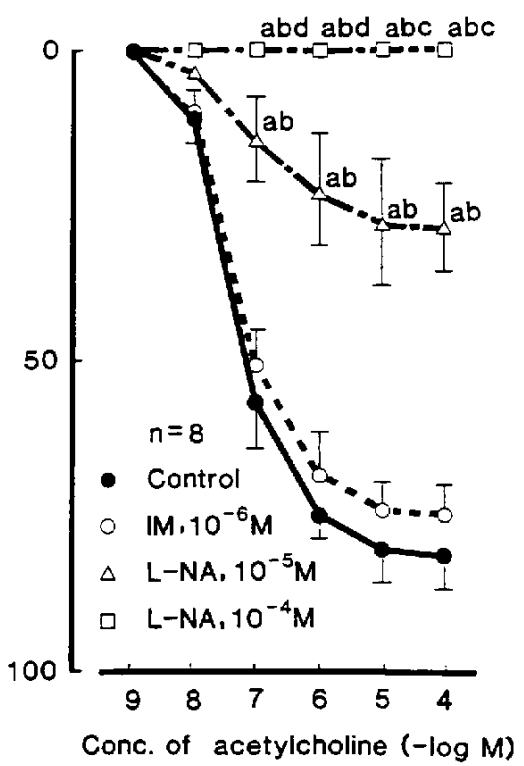

Fig. 1. Modification by endothelium denudation (left panel), indomethacin (IM), IM + methylene blue (middle) and IM $+N^{G}$ nitro-L-arginine (right) of the relaxant response to acetylcholine in canine internal thoracic arteries. The strips were partially contracted with 5HT. Relaxations induced by $10^{-4} \mathrm{M}$ papaverine were taken as $100 \%$. Significantly different from values obtained from endothelium-intact strips (left, unpaired $t$-test) and from control (middle and right, Tukey's method), ${ }^{2} \mathrm{P}<0.01$. Significantly different from values obtained from IM-treated strips (middle and right), ${ }^{b} \mathrm{P}<0.01$. Significantly different from values obtained from L-NA-treated strips (right), ${ }^{c} \mathbf{P}<0.01,{ }^{d} \mathbf{P}<\mathbf{0 . 0 5} . \mathrm{n}=$ number of strips from separate dogs. Vertical bars represent S.E.M. IM =indomethacin, $\mathrm{MB}=\mathrm{IM}+$ methylene blue, $\mathrm{L}-\mathrm{NA}=\mathrm{IM}+N^{G}$-nitro-I-arginine. 
Drugs used were acetylcholine chloride (Daiichi Seiyaku Co., Tokyo), $\mathrm{Ca}^{2+}$ ionophore (A23187), adenosine-5'triphosphate (Boehringer Mannheim, Germany), indomethacin (Sigma, St. Louis, MO, USA), serotonin creatinine-sulfate (Merck, Darmstadt, Germany), substance $P$, $N^{G}$-nitro-L-arginine (Peptide Institute, Inc., Minoh), methylene blue trihydrate, sodium nitrite (Nacalai Tesque, Inc., Kyoto) and papaverine hydrochloride (Dainippon Pharmaceutical Co., Osaka).

\section{RESULTS}

\section{Effects of acetylcholine and NO}

The addition of acetylcholine in concentrations ranging from $10^{-9}$ to $10^{-4} \mathrm{M}$ produced a concentration-related relaxation in ITA strips with intact endothelium, contracted partially with 5 HT (Fig. 1, left). The maximal relaxation was attained at $10^{-6} \mathrm{M}$. The apparent median effective concentration $\left(\mathrm{EC}_{50}\right)$ averaged $[6.7 \pm 2.6] \times 10^{-9} \mathrm{M}$. When the endothelium was removed mechanically, the relaxation induced by acetylcholine was abolished (Fig. 1, left). The relaxation of endothelium-intact strips was decreased by repeated trials; however, after the 3rd trial, the concentration-relaxation curve was stabilized. Therefore, the 3rd curve was taken as a control for evaluating the effects of antagonists. The acetylcholine-induced relaxation was not significantly attenuated by treatment with $10^{-6} \mathrm{M}$ indomethacin, but was abolished by additional treatment with $10^{-5} \mathrm{M}$ methylene blue (Fig. 1, middle).
Treatment with L-NA $\left(10^{-5}\right.$ and $\left.10^{-4} \mathrm{M}\right)$ attenuated the relaxation in a concentration-dependent manner (Fig. 1, right).

The relaxations induced by $10^{-8}$ and $10^{-7} \mathrm{M}$ acetylcholine were significantly greater in ITA than in coronary arterial strips with intact endothelium. However, the maximal relaxations of ITA $\left(88.4 \pm 2.9 \%\right.$ at $\left.10^{-5} \mathrm{M}\right)$ and coronary arteries $\left(84.9 \pm 2.3 \%\right.$ at $\left.10^{-4} \mathrm{M}\right)$ were almost identical (Fig. 2, left). The $\mathrm{EC}_{50}$ values in ITA and coronary arteries were $[3.9 \pm 2.7]$ and $[7.8 \pm 3.6] \times 10^{-8} \mathrm{M}$, respectively.

In ITA and coronary arterial strips contracted with 5HT, the addition of NO $\left(10^{-7}\right.$ to $\left.10^{-4} \mathrm{M}\right)$ produced a phasic, concentration-related relaxation. The maximal relaxations of ITA and coronary arteries were quite similar (Fig. 2, right). The $\mathrm{EC}_{50}$ values in these arteries were $[6.7 \pm 3.6] \times 10^{-6} \mathrm{M}$ and $[5.6 \pm 2.7] \times 10^{-7} \mathrm{M}$, respectively, the difference being statistically significant $(P<0.05)$ (Fig. 2, right).

\section{Effects of $A T P$}

The addition of ATP in concentrations ranging from $10^{-8}$ to $10^{-4} \mathrm{M}$ produced a concentration-related relaxation in 5HT-contracted ITA strips with intact endothelium. Typical recordings are shown in Fig. 3. When the endothelium was denuded, the relaxation was abolished (Figs. 3 and 4, left). The ATP-induced relaxation was not significantly attenuated by treatment with $10^{-6} \mathrm{M}$ indomethacin, but was suppressed dose-dependently by $10^{-5}$
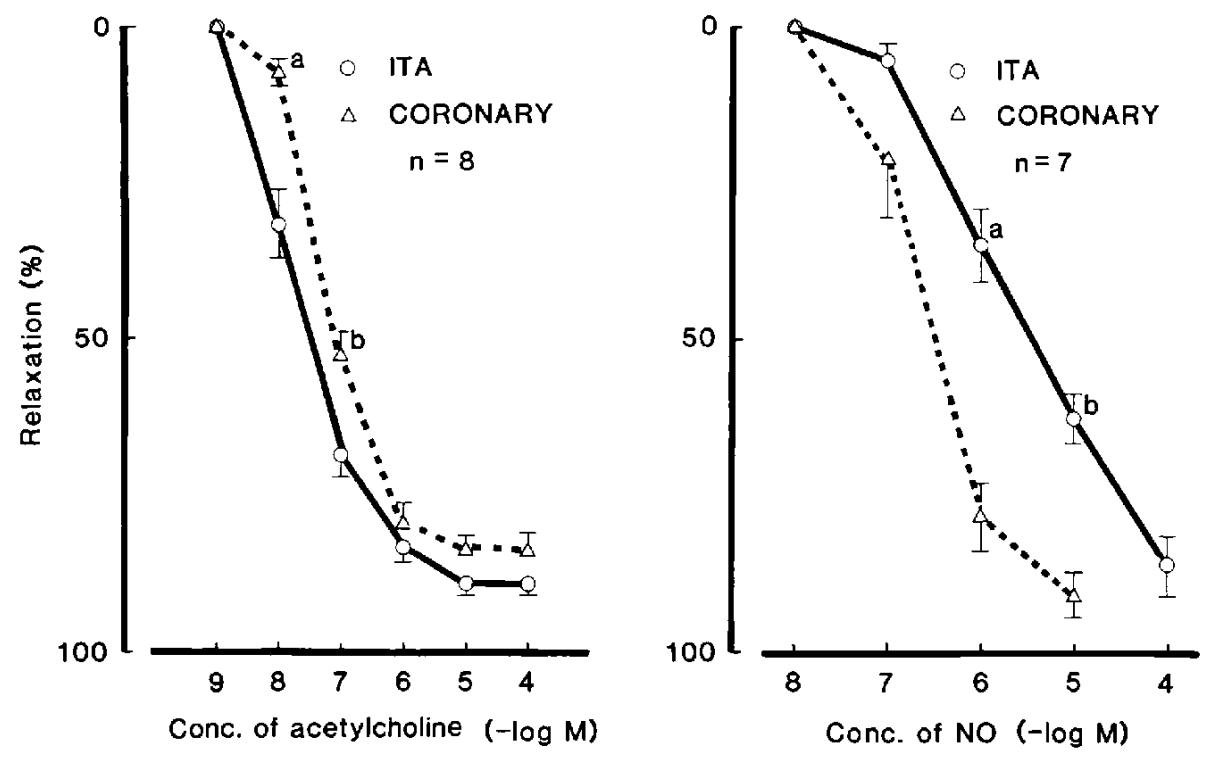

Fig. 2. Dose-response curves for acetylcholine (left panel) and nitric oxide (right) in canine internal thoracic and coronary arteries. The strips were partially contracted with 5 HT. Relaxations induced by $10^{-4} \mathrm{M}$ papaverine were taken as $100 \%$. Significantly different from values obtained from coronary arteries, ${ }^{\mathrm{a}} \mathrm{P}<0.01,{ }^{\mathrm{b}} \mathrm{P}<0.05$ (unpaired $t$-test). $\mathrm{n}=$ number of strips from separate dogs. Vertical bars represent S.E.M. NO= nitric oxide, ITA=internal thoracic arteries. 
INTERNAL THORACIC ARTERY

Endothelium $[+]$

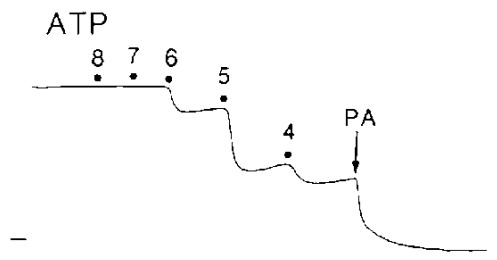

Endothelium (-)

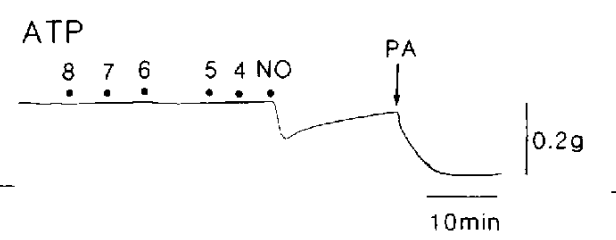

CORONARY ARTERY

Endothelium (+)

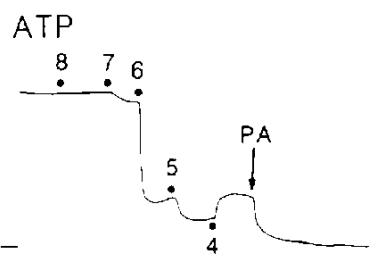

Endothelium [-]

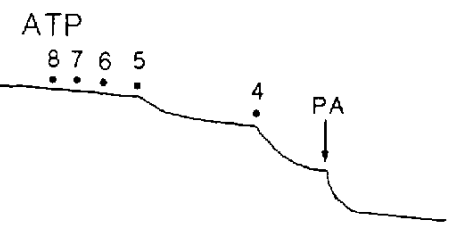

Fig. 3. Typical tracings of the response to ATP in canine internal thoracic (left panel) and coronary (right) arterial strips with and without the endothelium. Horizontal lines just left of each tracing represent the level before the addition of $5 \mathrm{HT}$. Concentrations of ATP from 8 to $4=10^{-8}, 10^{-7}, 10^{-6}, 10^{-5}$ and $10^{-4} \mathrm{M}$, respectively; NO $=10^{-6} \mathrm{M}$ nitric oxide; $\mathrm{PA}=10^{-4} \mathrm{M}$ papaverine.

INTERNAL THORACIC ARTERY

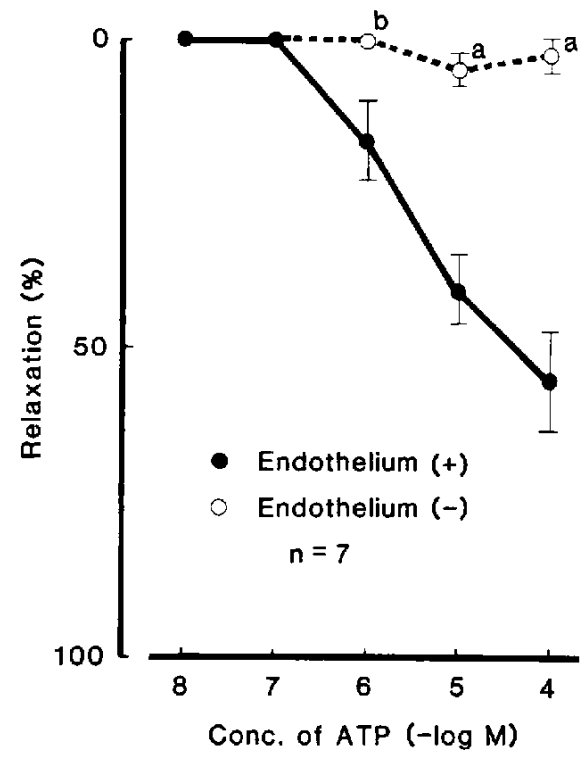

Endothelium (+)

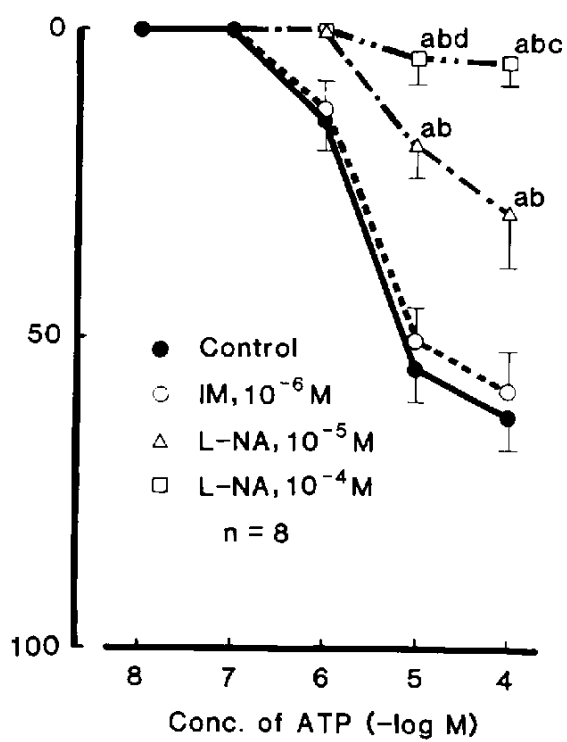

Fig. 4. Modification by endothelium denudation (left panel), indomethacin (IM) and IM $+N^{a}$-nitro-L-arginine (right) of relaxant responses to ATP in internal thoracic arterial strips. The strips were partially contracted with 5 HT. Relaxations induced by $10^{-4} \mathrm{M}$ papaverine were taken as $100 \%$. Significantly different from values obtained from strips with the endothelium (left), ${ }^{\mathrm{a}} \mathrm{P}<0.01,{ }^{\mathrm{b}} \mathrm{P}<0.05$ (unpaired $t$-test). Significantly different from values obtained from the control, ${ }^{\mathrm{a}} \mathrm{P}<0.01$; from IM-treated strips, ${ }^{b} \mathrm{P}<0.01$; and from L-NA $\left(10^{-5} \mathrm{M}\right.$ )-treated strips (right), ${ }^{\mathrm{C}} \mathrm{P}<0.01,{ }^{\mathrm{d}} \mathrm{P}<0.05$ (Tukey's method). $\mathrm{n}=$ number of strips from separate dogs. Vertical bars represent S.E.M. IM $=$ indomethacin, L-NA $=I M+N^{G}$-nitro-t-arginine. 


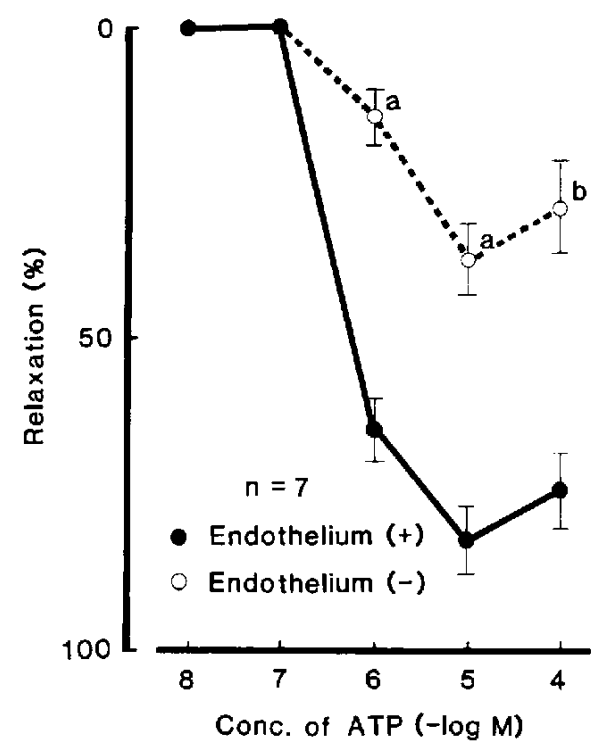

Endothelium ( + )

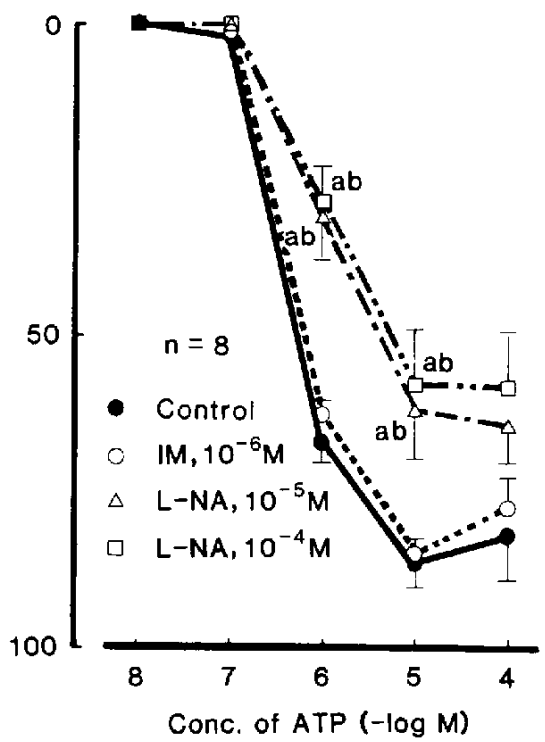

Fig. 5. Modification by endothelium denudation (left panel), indomethacin (IM) and IM $+N^{G}$-nitro-I-arginine (right) of relaxant responses to ATP in coronary arterial strips. The strips were partially contracted with $5 \mathrm{HT}$. Relaxations induced by $10^{-4} \mathrm{M}$ papaverine were taken as $100 \%$. Significantly different from values obtained from strips with the endothelium (left), " $P<0.01$; ${ }^{b} \mathrm{P}<0.05$ (unpaired $t$-test). Significantly different from values obtained from the control, ${ }^{\mathrm{a}} \mathrm{P}<0.01$ and from IM-treated strips (right), ${ }^{b} \mathrm{P}<0.01$ (Tukey's method). $\mathrm{n}=$ number of strips from separate dogs. Vertical bars represent S.E.M. IM =indomethacin, L-NA $=\mathrm{IM}+N^{G}$-nitro-L-arginine.

and $10^{-4} \mathrm{M}$ L-NA (Fig. 4, right). At $10^{-4} \mathrm{M}$ L-NA, the relaxation was abolished.

In coronary arterial strips with intact endothelium, ATP $\left(10^{-8}\right.$ to $\left.10^{-4} \mathrm{M}\right)$ produced a concentration-related relaxation (Fig. 3, right). The maximal relaxation was greater than that of ITA $(83.5 \pm 5.0 \%$ vs. $55.0 \pm 7.5 \%$, $\mathrm{n}=7, \mathrm{P}<0.01$ ). When the endothelium was denuded, the ATP-induced relaxation was significantly attenuated (44.7 $\pm 4.3 \%$ attenuation at $\left.10^{-5} \mathrm{M} \mathrm{ATP}\right)$, but was never abolished (Fig. 5, left). In the strips with intact endothelium, the ATP-induced relaxation was not influenced by treatment with $10^{-6} \mathrm{M}$ indomethacin, but was significantly attenuated by $10^{-5} \mathrm{M}$ L-NA. However, additional attenuations were not elicited by $10^{-4} \mathrm{M}$ L-NA (Fig. 5, right); the average inhibition at $10^{-5} \mathrm{M}$ ATP was $30.2 \pm 4.8 \%(n=8)$.

Effects of substance $P$ and the $\mathrm{Ca}^{2+}$ ionophore $\mathrm{A} 23187$

The addition of $10^{-7} \mathrm{M}$ substance $P$ produced a phasic relaxation in ITA with intact endothelium, which was suppressed by endothelium denudation (Fig. 6). Treatment with L-NA $\left(10^{-5}\right.$ and $\left.10^{-4} \mathrm{M}\right)$ significantly inhibited the relaxation, whereas indomethacin $\left(10^{-6} \mathrm{M}\right)$ was without effect (Fig. 7, left). In the coronary arterial strips, substance $P\left(10^{-7} \mathrm{M}\right)$ produced a phasic, endothelium-depend- ent relaxation (Fig. 6). The relaxation was not attenuated by indomethacin, but was markedly suppressed by $10^{-5} \mathrm{M}$ L-NA (Fig. 7, right). Relaxations of ITA and coronary arteries were $62.8 \pm 6.4 \% \quad(n=7)$ and $84.3 \pm 2.7 \%(n=7)$, respectively; the difference was statistically significant $(\mathrm{P}<0.01)$.

The addition of A23187 produced a concentration-related relaxation in ITA and coronary arterial strips with intact endothelium (Fig. 8). The relaxation in coronary arterial strips $\left(87.9 \pm 2.4 \%\right.$ at $\left.10^{-7} \mathrm{M}, \mathrm{n}=7\right)$ was significantly greater than that in ITA $\left(61.8 \pm 2.3 \%\right.$ at $10^{-7} \mathrm{M}, \mathrm{n}=7$, $P<0.01$ ). Endothelium denudation abolished the relaxation in ITA and reversed it to a slight contraction in coronary arteries (Fig. 8).

\section{DISCUSSION}

In canine ITA, relaxations induced by acetylcholine were abolished by treatment with methylene blue in a concentration $\left(10^{-5} \mathrm{M}\right)$ sufficient to significantly inhibit the activity of soluble guanylate cyclase (8), L-NA, an NO synthase inhibitor, or removal of the endothelium, but were not attenuated by indomethacin, a cyclooxygenase inhibitor. These findings suggest that the relaxations caused by acetylcholine are not mediated by prostaglan- 
Substance $P$

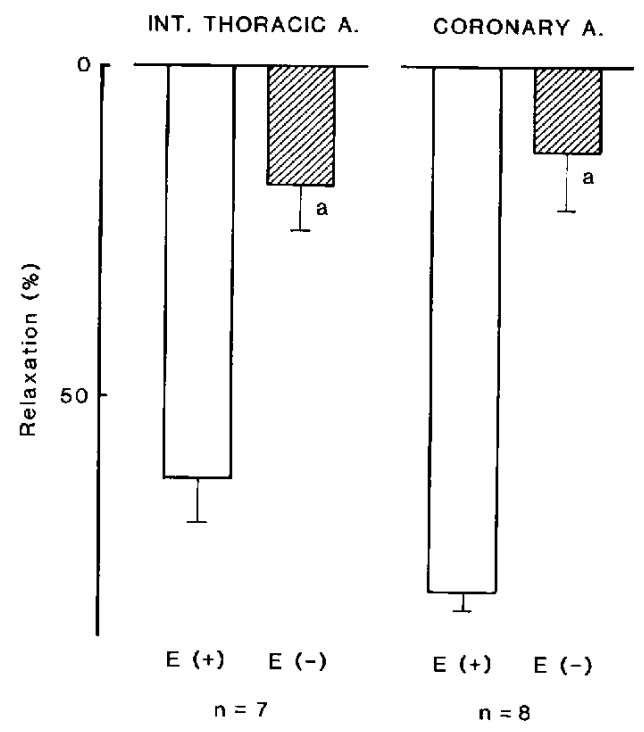

Fig. 6. Modification by endothelium denudation of the relaxant response to $10^{-7} \mathrm{M}$ substance $P$ in internal thoracic (left panel) and coronary arterial strips (right) contracted with $5 \mathrm{HT}$. The preparations with and without the endothelium were obtained from the same dogs. Relaxations induced by $10^{-4} \mathrm{M}$ papaverine were taken as $100 \%$. Significantly different from values in strips with endothelium, ${ }^{a} \mathbf{P}<0.01$ (unpaired $t$-test). Numbers in parentheses indicate the number of strips obtained from different individuals. $E(+)$, strips with the endothelium; $E(-)$, strips without the endothelium. Vertical bars represent S.E.M. din (PG) $I_{2}$ but by EDRF or NO. Similar results were obtained in canine coronary arteries (present study and refs. 9 and 10). In the monkey coronary arteries, the acetylcholine-induced relaxation is mediated by $\mathrm{PGI}_{2}$ as well as EDRF (11). The relaxant responses to low concentrations of acetylcholine were significantly greater in ITA than in coronary arteries. In contrast, the relaxations induced by substance $\mathrm{P}, \mathrm{A} 23187$ or NO in ITA were significantly less than those in coronary arteries. However, the maximal relaxation by acetylcholine in ITA was approximately the same as that in coronary arteries. These findings suggest that ITA in response to acetylcholine produces NO in the endothelium (EDNO) to a greater extent than coronary arteries, possibly due to higher sensitivity of muscarinic receptors located in the endothelium of ITA.

Human ITA responds to acetylcholine with endothelium-dependent relaxations $(12-14)$. The magnitude of the maximal relaxation $(86 \pm 4 \%(12), 95 \pm 2 \%(13), 67 \pm 6 \%$ (14)) is comparable to that in canine ITA $(88.4 \pm 2.9 \%)$. The relaxation of human ITA is postulated to be associated with EDNO, but not with $\mathrm{PGI}_{2}$, as observed in canine ITA and coronary arteries (present study and ref. 10). On the other hand, isolated human coronary arteries respond to acetylcholine with contractions $(15,16)$, as in the arteries in vivo (17). The contraction is reportedly greater in the arteries of patients with atherosclerosis or hypercholes-
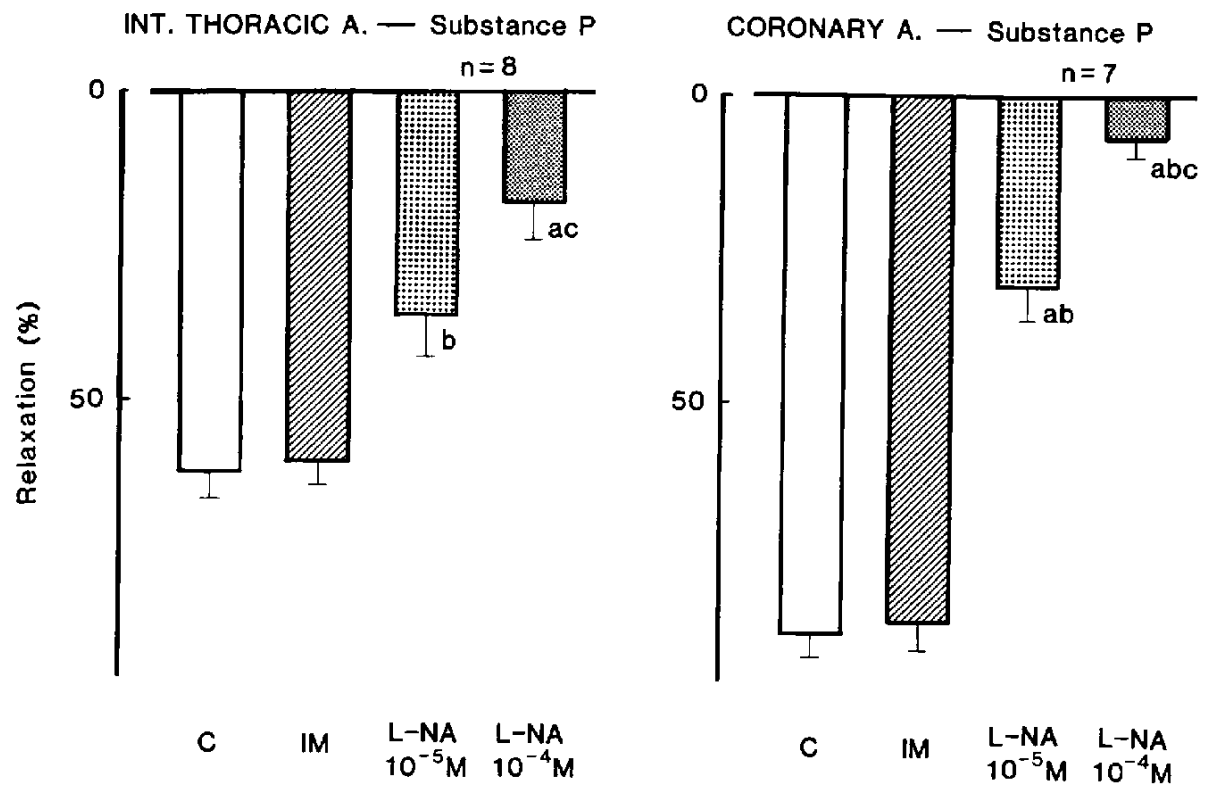

Fig. 7. Modification by indomethacin (IM) and IM $+N^{G}$-nitro-L-arginine of relaxant responses to $10^{-7} \mathrm{M}$ substance $\mathrm{P}$ in internal thoracic (left panel) and coronary arterial strips (right) contracted with $5 \mathrm{HT}$. Relaxations induced by $10^{-4} \mathrm{M}^{-4}$ apaverine were taken as $100 \%$. Significantly different from values obtained from the control, ${ }^{a} P<0.01,{ }^{b} P<0.05$; from IM-treated strips, ${ }^{b} \mathrm{P}<0.01$; and from $10^{-5} \mathrm{M}$ L-NA-treated strips, ${ }^{\mathrm{C}} \mathrm{P}<0.01$ (Tukey's method). $\mathrm{n}=$ number of strips from separate dogs. Vertical bars represent S.E.M. $\mathrm{C}=$ control, $\mathbf{I M}=$ indomethacin, L-NA $=\mathrm{IM}+N^{G}$-nitro-L-arginine. 


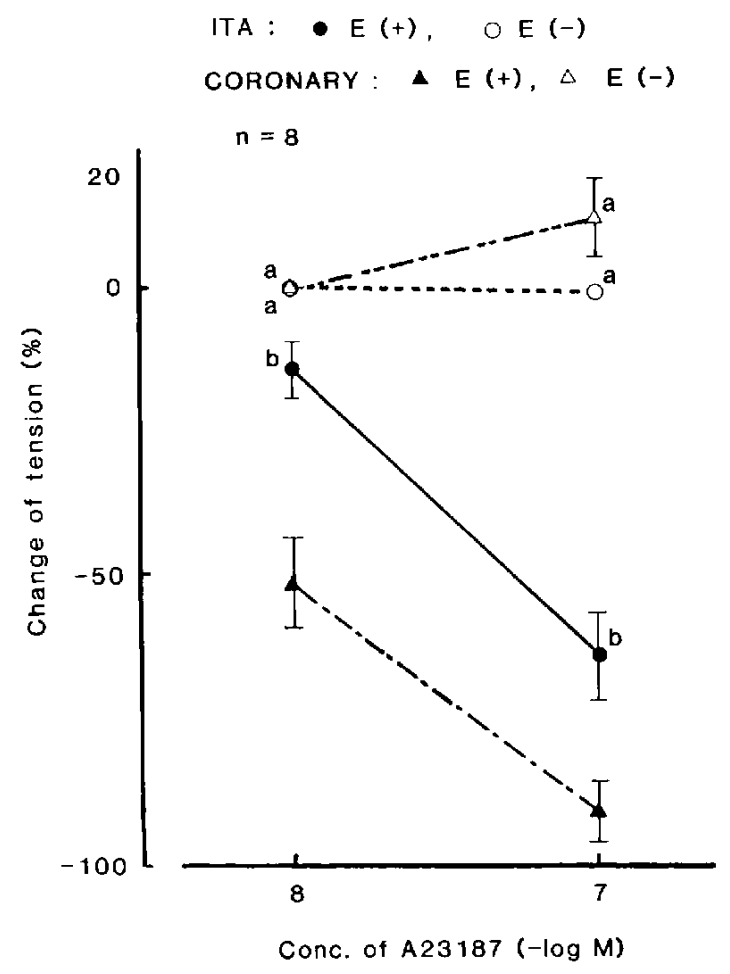

Fig. 8. Modification by endothelium denudation of relaxant responses to A23187 in strips of internal thoracic and coronary arteries. The strips partially contracted with $5 \mathrm{HT}$. Contractions induced by $30 \mathrm{mM} \mathrm{K}^{+}$were taken as $100 \%$ for contraction, and relaxations induced by $10^{-4} \mathrm{M}$ papaverine were taken as $100 \%$ for relaxation. Significantly different from values obtained from strips with the endothelium, "P $<0.01$ (unpaired $t$-test). Significantly different from values obtained from coronary arterial strips with endothelium, ' $\mathbf{P}<0.01, n=$ number of strips from separate dogs. $E(+)$, strips with endothelium; $E(-)$, strips without the endothelium. Vertical bars represent the S.E.M. ITA = internal thoracic arteries.

terolemia than in healthy subjects $(18,19)$. In cardiac surgery, ITA is used as a bypass graft in CABG, and the grafts have higher early and late patency rates than saphenous vein grafts $(1,2)$. The late survival rate of CABG is significantly better in the case of ITA grafts (3, 4), probably by the fact that veins with intact endothelium respond to EDRF-releasing endogenous substances, such as acetylcholine or histamine, with contractions or less relaxations than arteries $(12,13)$. Therefore, when ITA is used for CABG, endothelial integrity would be important. In addition to vasodilatation, the anti-platelet activity $(20,21)$ of EDRF would also be important for better patency upon CABG.

ATP relaxed canine ITA and coronary arteries concentration-dependently; the maximal relaxation in ITA was less. In the ITA, relaxations induced by ATP were not attenuated by treatment with indomethacin, but were abolished by endothelial denudation and treatment with L-NA. In the coronary arteries, ATP-induced relaxations were attenuated partially by endothelial denudation or treatment with L-NA, but were not abolished. These findings suggest that the relaxations induced by ATP in the ITA are mediated by EDNO, whereas those in coronary arteries are due partly to a mediation of EDNO and to the other mechanisms, such as a direct action on smooth muscle. This may be a reason why the magnitude of relaxations by ATP in the coronary arteries is greater. It has been reported that ATP relaxes canine femoral, pulmonary, saphenous, and splenic arteries by activating $P_{2^{-}}$ purinoceptors located on the endothelium (22). However, the present study demonstrated that ATP partially relaxed canine coronary arteries in an endothelium-independent manner. According to White and Angus, the ATP-induced relaxation of canine coronary arteries of large diameter is endothelium-dependent, whereas, the relaxation of canine coronary arteries of small diameter is independent of the endothelium (23).

Substance $\mathbf{P}$ relaxed canine ITA and coronary arteries only in the presence of intact endothelium. The relaxant responses were unaffected by indomethacin, but were almost abolished by treatment with L-NA. Similar EDRF-mediated relaxations have been observed in human coronary $(15,16,24)$, canine renal $(9)$, femoral (25) and mesenteric arteries in response to substance $P$.

The findings so far obtained indicate that acetylcholine, ATP and substance $P$ appear to relax canine ITA by a mediation of EDNO, but not $\mathrm{PGI}_{2}$. Coronary arterial relaxations induced by ATP are mediated by the indirect action via EDNO and possibly by the direct action on the smooth muscle. The present study analyzed the mechanism of action of the substances (acetylcholine, ATP and substance $P$ ) released possibly from cholinergic, purinergic and peptidergic nerves. The ability of ITA to liberate EDNO in response to these substances may contribute to superior patency and survival rate in CABG.

\section{REFERENCES}

1 Barner, H.B., Swartz, M.T., Nudd, J.G. and Tyras, D.H.: Late patency of the internal mammary artery as a coronary bypass conduit. Ann. Thorac. Surg. 34, 408-412 (1982)

2 Singh, R.N., Sosa, J.A. and Green, G.E.: Long-term fate of the internal mammary artery and saphenous vein grafts. J. Thorac. Cardiovasc. Surg. 83, 359-363 (1983)

3 Lytle, B.W., Loop, F.D., Thurer, R.L., Groves, L.K., Taylor, P.C. and Cosgrove, D.M.: Isolated left anterior descending coronary atherosclerosis. Long-term comparison of internal mammary artery and venous autografs. Circulation 61, 869874 (1980)

4 Jones, J.W., Ochsner, J.L., Mills, N.L. and Hughes, L.: Clinical comparison with saphenous vein and internal mammary artery as a coronary graft. J. Thorac. Cardiovasc. Surg. 80, 
334-341 (1980)

5 Sims, R.N.: A comparison of coronary and internal mammary arteries and implications of the results in the etiology of arteriosclerosis. Am. Heart J. 105, 560-566 (1983)

6 Furchgott, R.F. and Zawadzki, J.V.: The obligatory role of endothelial cells in the relaxation of arterial smooth muscle by acetylcholine. Nature 288, 373-376 (1980)

7 Furchgott, R.F.: Studies on relaxation of rabbit aorta by sodium nitrites: the basis for the proposal that the acid-activatable inhibitory factor from bovine retractor penis is inorganic nitrite and the endothelium-derived relaxing factor is nitric oxide. In Vasodilatation, Edited by Vanhoutte, P.M., pp. 401-414, Raven Press, New York (1987)

8 Guetter, C.A., Kadowitz, P.J. and Ignarro, L.J.: Methylene blue inhibits coronary arterial relaxation and guanylate cyclase activation by nitroglycerin, sodium nitrite and amyl nitrite. Can. J. Physiol. Pharmacol. 59, 150-156 (1981)

9 Angus, J.A., Cocks, T.M., Satoh, K. and White, T.D.: Receptor heterogeneity and EDRF release. In Sixth International Symposium on Vascular Neuroeffector Mechanisms, Edited by Bevan, J.A., Magewski, H.M., Maxwell, R.A. and Story, D.F., pp. 85-91, IRL Press, Washington D.C. (1988)

10 Angus, J.A. and Cocks, T.M.: Role of endothelium in vascular responses to norepinephrine, serotonin and acetylcholine. Bibl. Cardiol. 38, 43-52 (1984)

11 Okamura, T., Minami, Y. and Toda, N.: Endothelium-dependent and -independent mechanisms of action of acetylcholine in monkey and dog isolated arteries. Pharmacology 38, 279-288 (1989)

12 Lüscher, T.F., Diedrich, D., Siebenmann, R., Lehmann, K., Stulz, P., von Segesser, L., Yang, Z., Turina, M., Gräadel, E., Weber, E. and Bühler, F.R.: Difference between endotheliumdependent relaxation in arterial and in venous coronary bypass grafts. N. Engl. J. Med. 319, 462-467 (1988)

13 Yang, Z., von Segesser, L., Bauer, E., Stulz, P., Turina, M. and Lüscher, T.F.: Different activation of the endothelial L-arginine and cyclooxygenase pathway in the human internal mammary artery and saphenous vein. Circ. Res. 68, 52-60 (1991)

14 Lüscher, T.F., Yang, Z., Tschudi, M., von Segesser, L., Stulz, P., Boulanger, C., Siebenmann, R., Turina, M. and Bühler, F.R.: Interaction between endothelin-1 and endothelium-derived relaxing factor in human arteries and veins. Circ. Res. 66,
$1088-1094$ (1990)

15 Angus, J.A., Cocks, T.M., McPherson, G.A. and Broughton, A.: The acetylcholine paradox. A constrictor of human small coronary arteries even in the presence of endothelium. Clin. Exp. Pharmacol. Physiol. 18, 33-36 (1991)

16 Toda, N. and Okamura, T.: Endothelium-dependent and -independent responses to vasoactive substances of isolated human coronary arteries. Am. J. Physiol. 257, H988-H995 (1989)

17 Yasue, H., Horio, Y., Nakamura, N., Fujii, H., Imoto, N., Sonoda, R., Kugiyama, K., Obata, K., Morikami, Y. and Kimura, T.: Induction of coronary artery spasm by acetylcholine in patients with variant angina. Possible role of the parasympathetic nervous system in the pathogenesis of coronary artery spasm. Circulation 74, 955-963 (1986)

18 Ludmer, P.L., Selwyn, A.P., Shook, T.L., Wayne, R.R., Mudge, G.H., Alexander, R.W. and Ganz, P.: Paradoxical vasoconstriction induced by acetylcholine in atherosclerotic coronary arteries. N. Engl. J. Med. 315, 1046-1051 (1986)

19 Drexler, H. and Zeiher, A.M.: Endothelial function in human coronary arteries in vivo. Focus on hypercholesterolemia. Hypertension 18, Supp. II, II-90-II-99 (1991)

20 Radomski, M.W., Palmer, R.M.J. and Moncada, S.: The role of nitric oxide and CGMP in platelet adhesion to vascular endothelium. Biochem. Biophys. Res. Commun. 143, 1482-1489 (1987)

21 Hogan, J.C., Lewis, M.J. and Henderson, A.H.: In vivo EDRF activity influences platelet function. Br. J. Pharmacol. 94, $1020-1022$ (1988)

22 Vanhoutte, P.M. and Miller, V.M.: Heterogeneity of endothelium-dependent responses in mammalian blood vessels. J. Cardiovasc. Pharmacol. 7, Supp. 3, S12-S23 (1985)

23 White, T.D. and Angus, J.A.: Relaxant effects of ATP and adenosine in canine large and small coronary arteries in vitro. Eur. J. Pharmacol. 143, 119-126 (1987)

24 Chester, A.H., O'Neil, G.S., Tadjarimi, S., Paimer, R.M.J., Moncada, S. and Yacoub, M.H.: The role of nitric oxide in mediating endothelium dependent relaxations in the human epicardial coronary artery. Int. J. Cardiol. 29, 305-309 (1990)

25 Angus, J.A., Campbell, G.R., Cocks, T.M. and Manderson, J.A.: Vasodilatation by acetylcholine is endothelium-dependent. A study by sonomicretry in canine femoral artery in vivo. $\mathbf{J}$. Physiol. (Lond.) 344, 209-222 (1983) 